\title{
HUBUNGAN FUNGSI KELUARGA DENGAN KECEMASAN MENGHADAPI MENARCHE PADA REMAJA PUTRI USIA SEKOLAH DASAR DI SD NEGERI 064988 MEDAN
}

\author{
Verany Melinda Purba1, Sri Rahayu Sanusi², Evawany Y Aritonang ${ }^{3}$ \\ ${ }^{1}$ Jurusan kesehatan Reproduksi, Universitas Sumatera Utara Medan \\ Email: veraarmansyah@gmail.com \\ ${ }^{2}$ Departemen Biostatistik dan Kependudukan, Universitas Sumatera Utara Medan \\ Email: ayusans@yahoo.com \\ ${ }^{3}$ Departemen Gizi, Universitas Sumatera Utara Medan \\ Email: evawany@gmail.com
}

\begin{abstract}
ABSTRAK
Menarche adalah menstruasi pertama yang biasa terjadi dalam rentang usia 10-16 tahun atau pada masa awal remaja ditengah masa pubertas sebelum memasuki masa reproduksi. Datangnya menarche dapat menimbulkan kecemasan. Fungsi keluarga adalah peran keluarga dalam memberikan informasi untuk menjaga kesehatan reproduksi. Fungsi keluarga berhubungan dengancemas dan tidak cemas remaja dalam menghadapi menarche. Penelitian ini bertujuan untuk mengetahui Hubungan Fungsi Keluarga dengan Kecemasan Menghadapi Menarche pada Remaja Putri Usia Sekolah di SD Negeri 064988 Medan. Jenis penelitian adalah penelitian kuantitatif dengan metode cross sectional. Populasi dalam penelitian ini adalah seluruh siswi kelas 5 dan 6 di SD Negeri 064988 berjumlah 85 orang dan seluruhnya dijadikan sampel. Data diperoleh dengan wawancara menggunakan kuesioner, pada uji bivariat dianalisis dengan Chi Square.Hasil penelitian diketahui 41 responden yang termasuk kategori fungsi keluarga baik terdapat 25 orang tidak cemas dan 16 orang mengalami cemas. Kemudian dari 44 responden yang termasuk kategori fungsi keluarga kurang terdapat 10 orang tidak cemas dan 34 orang mengalami cemas. Hasil penelitian menunjukkan bahwa terdapat hubungan antara fungsi keluarga dengan kecemasan menghadapi menarche diperoleh nilai probabilitas p (0,0001). Kepada orangtua terutama ibu, serta anggota keluarga lainnya diharapkan dapat memberikan informasi kesehatan reproduksi kepada remaja putri agar menambah pengetahuan terutama tentang menstruasi pertama (menarche) sehingga dapat mengurangi kecemasan menghadapi menarche.
\end{abstract}

Kata Kunci: Menarche, Fungsi Keluarga, Kecemasan

\section{PENDAHULUAN Latar Belakang}

Menarche adalah menstruasi pertama yang biasa terjadi dalam rentang usia 10-16 tahun atau pada masa awal remaja ditengah masa pubertas sebelum memasuki masa reproduksi. Menarche merupakan perdarahan periodik dan siklik dari uterus disertai pengelupasan atau deskuamasi endometrium (Sukarni \& ZH, 2013). Remaja putri di Indonesia saat ini cenderung mengalami menarche pada usia lebih muda. Hasil penelitian di SMPN I Kampar Riau terhadap 60 orang siswi didapatkan 20 orang mengalami menarche dini, dan anak perempuan yang bergizi baik usia rata-rata menarche 12 tahun 4 bulan (Afrinis, 2014). Hasil penelitian di SMP Safiyyatul Amaliyah Medan ditemukan bahwa 38,1\% usia saat menarche remaja berada pada usia 11 tahun dari sampel berjumlah 63 orang (Putri, 2015).

Masa remaja atau masa puber, merupakan masa penghubung antara masa anak-anak dengan dewasa. Pertumbuhan dan perkembangan pada masa remaja sangat pesat, baik fisik maupun psikologis. Perkembangan yang pesat ini berlangsung pada usia 11-16 tahun pada laki-laki dan 10-15 tahun pada perempuan. Anak perempuan lebih cepat dewasa dibandingkan anak laki-laki, pada masa pubertas mulai ada rasa tertarik terhadap lawan jenis. Disaat seorang remaja perempuan mengalami menarche untuk pertama kali, biasanya akan timbul perasaan bingung, gelisah, tidak nyaman selalu meyelimuti. Menarche adalah hal yang wajar terjadi dan dialami setiap perempuan normal dan tidak perlu digelisahkan.

Keluarga adalah unit terkecil dalam masyarakat yang terdiri dari suami, istri dan anaknya, atau ayah dan anaknya, atau ibu dan anaknya (UU No. 52 tahun 2009). Fungsi keluarga berperan 
dalam memberikan informasi menjaga kesehatan reproduksi. Hasil penelitian di Yogyakarta menunjukkan peran orangtua dalam pendidikan menstruasi berpengaruh terhadap siswi saat menstruasi. Siswi yang peran orangtuanya baik maka akan berperilaku baik juga saat menstruasi (Estri, 2012).

Hasil penelitian di SD Negeri 066667 Medan dan SD Negeri 066433 Medan menemukan fungsi keluarga mempunyai pengaruh terhadap pemahaman menarche pada remaja putri usia sekolah dasar. Fungsi keluarga adalah peran keluarga dalam memberikan informasi untuk menjaga kesehatan reproduksi Pulungan, 2012).Akibat kurangnya keluarga dalam menjalankan fungsi dan kurangnya pemahaman tentang menarche, yang merupakan salah satu informasi tentang kesehatan reproduksi sejak awal pada remaja putri adalah perasaan cemas dan takut akan muncul bila kurangnya pemahaman remaja putri tentang menarche, sehingga diperlukan kesiapan mental. Untuk itu, remaja perlu dipersiapkan dalam menghadapi datangnya menarche (Prasetyo, 2016).

Kecemasan (ansietas/anxiety) adalah gangguan alam perasaan (affective) yang ditandai dengan perasaan ketakutan ajuan tau kekhawatiran yang mendalam dan berkelanjutan, tidak mengalami gangguan dalam menilai realitas (Reality Testing Ability/RTA), kepribadian masih utuh, perilaku dapat terganggu tetapi dalam batas-batas normal (Hawari, 2013).

Kecemasan menghadapi menarche juga memengaruhi kondisi sosial remaja putri. Hal ini dapat dibuktikan dari hasil penelitian pada remaja putri di Istambul merasakan cemas, takut dan menangis pada saat mengalami menarche yang mengakibatkan murung, ingin menyembunyikan kalau mereka sudah mendapat haid pertama kepada orang lain (Karoc etall, 2014). Sehingga apabila masalah kecemasan menghadapi menarche banyak terjadi dan tidak diperhatikan, hal ini juga merupakan masalah kesehatan masyarakat.

Berdasarkan hal diatas maka penelitian ini bertujuan untuk mengetahui hubungan fungsi keluarga dengan kecemasan menghadapi menarche pada remaja putri usia sekolah dasar di SD Negeri 064988 Medan.

\section{Rumusan Masalah}

Kejadian menarche yang mengalami pergeseran ke arah yang lebih cepat (dini) pada remaja putri, menimbulkan kecemasan awal. Sehingga permasalahan penelitian adalah bagaimanakah hubungan fungsi keluarga dan pemahaman menarchedengan kecemasan menghadapi menarche.

\section{METODELOGI PENELITIAN}

Jenis penelitian yang digunakan dalam penelitian ini adalah penelitian kuantitatif dengan metode cross sectional. Desain penelitian cross sectional adalah penelitian yang dilakukan pada satu waktu dan satu kali untuk mencari hubungan antara variabel independen dengan variabel dependen. Penelitian dilaksanakan di SD Negeri 064988 Medan di Jalan Karya Jaya, Kecamatan Medan Johor. Penelitian ini dilaksanakan dari bulan November 2016 hingga Juni 2017.

Populasi dalam penelitian ini adalah seluruh siswi kelas 5 dan 6 di SD Negeri 064988 berjumlah 85 orang, dan seluruhnya dijadikan sampel. Variabel independen dalam penelitian ini adalah fungsi keluarga dan variabel dependen dalam penelitian ini adalah kecemasan menghadapi menarche pada remaja putri. 
Metode pengumpulan data dalam penelitian ini diambil dari data primer dan sekunder. Data primer diperoleh dari hasil wawancara dengan responden yang berpedoman pada kuosioner yang telah dipersiapkan. Adapun sumber data primer didapat dari hasil jawaban responden yang diteliti. Data sekunder adalah data yang didapat dari sumber-sumber terkait berupa data siswa di SD Negeri 064988 Medan.

Analisis univariat digunakan untuk mengetahui gambaran deskriptif dengan menampilkan tabel distribusi frekuensi dan persentase dari masing-masing variabel independen dan variabel dependen. Analisi bivariat diigunakan untuk mendapat informasi tentang hubungan variabel independen yaitu fungsi keluarga dengan variabel dependen yaitu kecemasan mengahadapi menarche dengan menggunakan uji Chi Square dengan $\alpha=0,05$.

\section{HASIL DAN PEMBAHASAN}

Hasil penelitian menunjukkan umur remaja putri bahwa paling banyak remaja putri berumur 11 tahun sebanyak 42 orang $(49,4 \%)$ kemudian umur 12 tahun sebanyak 24 orang $(28,2 \%)$, dan umur 10 tahun sebanyak 19 orang $(22,4 \%)$. Hasil pengukuran fungsi keluarga lebih banyak yang termasuk dalam kategori kurang sebanyak 44 orang $(51,76 \%)$ dan termasuk dalam kategori baik sebanyak 41 orang $(48,24 \%)$.

Hasil tabulasi silang antara fungsi keluarga dengan kecemasan menghadapi menarche pada remaja putri menunjukkan bahwa dari 41 orang yang termasuk kategori fungsi keluarga baik terdapat 25 orang $(61,0 \%)$ yang tidak cemas dan 16 orang $(39,0 \%)$ mengalami cemas. Kemudian dari 44 responden yang termasuk dalam kategori fungsi keluarga kurang terdapat 10 orang $(22,7 \%)$ yang tidak cemas dan 34 orang $(77,3 \%)$ mengalami cemas. Berdasarkan analisis bivariat antara fungsi keluarga dengan kecemasan menghadapi menarche diperoleh nilai probabilitas $p$ $(0,0001)$. Artinya ada hubungan antara fungsi keluarga dengan kecemasan menghadapi menarche.

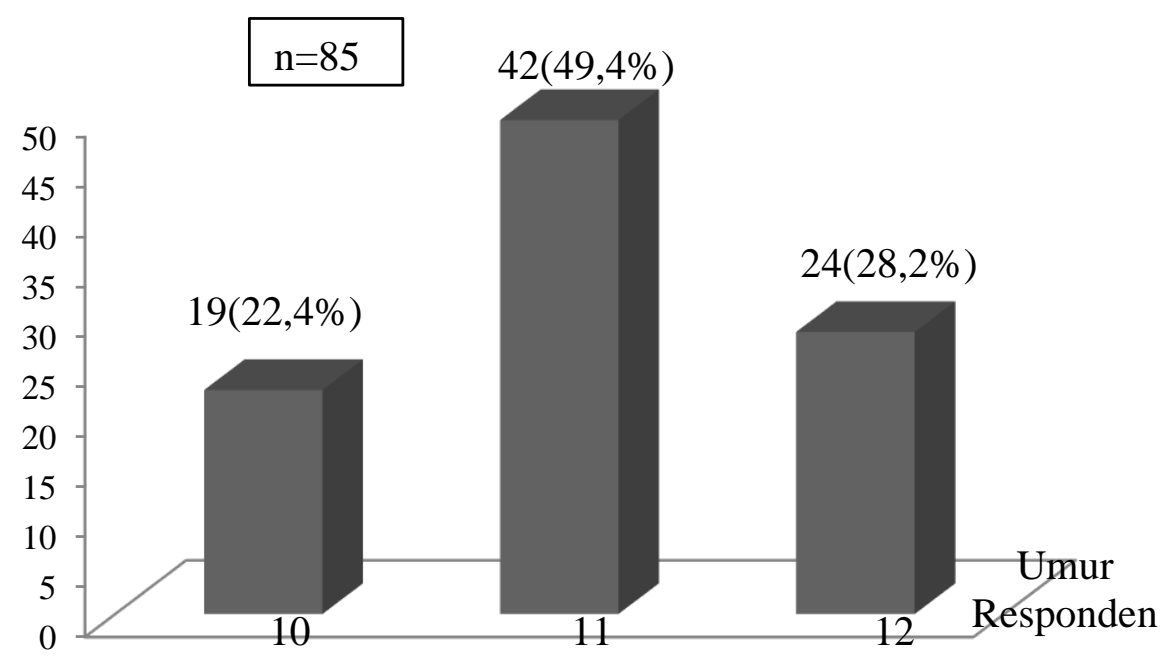

Gambar 1. Distribusi Frekuensi Umur Responden 


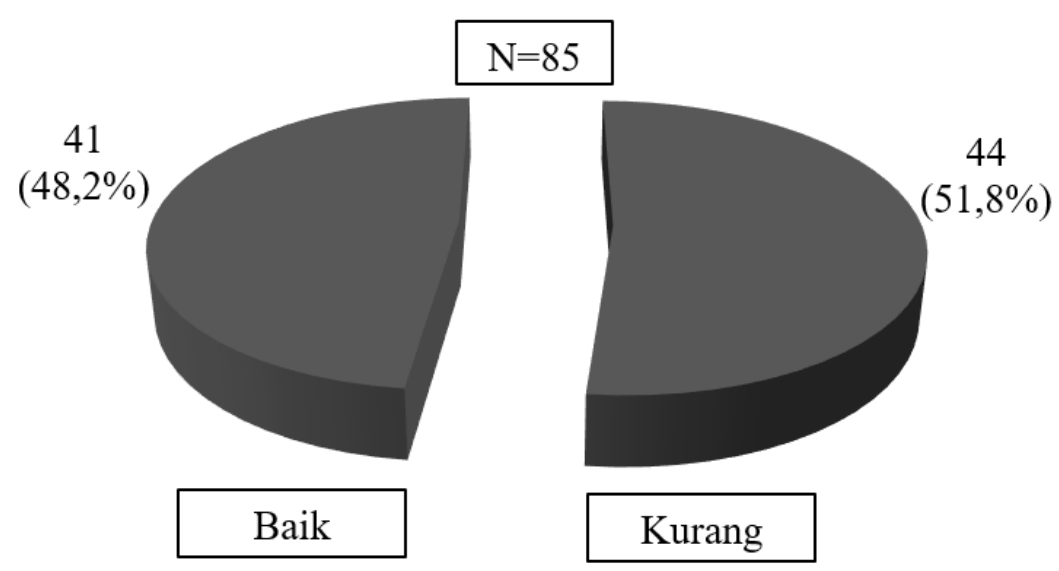

Gambar 2. Distribusi Kategori Fungsi Keluarga

Tabel 1. Hubungan Fungsi Keluarga dengan Kecemasan Menghadapi Menarche pada Remaja Putri Usia Sekolah Dasar di SD Negeri 064988 Medan

\begin{tabular}{|c|c|c|c|c|c|c|c|}
\hline \multirow{3}{*}{ Variabel } & \multicolumn{4}{|c|}{$\begin{array}{c}\text { KecemasanMenghadapiMenarc } \\
\text { he }\end{array}$} & & & \multirow[b]{2}{*}{$\boldsymbol{P}$} \\
\hline & \multicolumn{2}{|c|}{ TidakCemas } & \multicolumn{2}{|c|}{ Cemas } & \multicolumn{2}{|c|}{ Total } & \\
\hline & $\mathbf{n}$ & $\%$ & $\mathbf{n}$ & $\%$ & $\mathbf{n}$ & $\%$ & \\
\hline \multicolumn{8}{|l|}{ FungsiKeluarga } \\
\hline Baik & 25 & 61,0 & 16 & 39,0 & 41 & 100,0 & 0,0001 \\
\hline Kurang & 10 & 22,7 & 34 & 77,3 & 44 & 100,0 & \\
\hline
\end{tabular}

Berdasarkan hasil uji bivariat dengan menggunakan analisis Chi-Square yang telah dilakukan menunjukkan bahwa nilai $\mathrm{p}(0,0001)<0,05$ yang artinya ada hubungan antara fungsi keluarga dengan kecemasan menghadapi menarche pada remaja putri usia sekolah dasar di SD Negeri 064988 Medan.

Fungsi keluarga dalam penelitian ini merupakan gabungan dari fungsi cinta kasih, fungsi perlindungan, fungsi reproduksi, fungsi sosialisasi dan pendidikan. Mendapatkan cinta kasih adalah hak anak dan kewajiban orang tua untuk memenuhinya. Fungsi cinta kasih meliputi menumbuhkembangkan potensi simbol cinta kasih sayang yang telah ada di antara anggota keluarga dalam simbol nyata, seperti ucapan, dan tingkah laku secara optimal dan terus menerus (Ali, 2010).

Hal ini sejalan dengan hasil penelitian yang menyatakan bahwa berdasarkan analisis bivariat dengan menggunakan uji chi-square terhadap dukungan keluarga dengan tingkat kecemasan pada remaja putri dalam menghadapi menarche di MI Salafiyah Simbang Kulon 02 Kabupaten Pekalongan didapatkan nilai $\rho$ value $=0,0001$, dengan demikian $\rho$ value $<\alpha(0,05)$ sehingga Ha gagal ditolak. Hal ini menunjukkan ada hubungan dukungan keluarga dengan tingkat kecemasan pada remaja putri dalam menghadapi menarche di MI Salafiyah Simbang Kulon 02 Kabupaten Pekalongan (Ulfa et all, 2012).

Remaja yang mendapatkan dukungan dari keluarga, khususnya ibu menjadikan remaja merasa aman dan nyaman dirumah. Remaja lebih dekat dengan ibu, sehingga akan menyampaikan 
keluhan pada ibunya, termasuk tentang menarche. Ibu akan memberikan penjelasan kepada anaknya tentang kondisi yang akan dialaminya. Oleh karena itu, remaja yang mendapatkan dukungan dari ibu dapat memiliki kesiapan yang lebih baik dalam mengahadapi menarche dibandingkan yang yang kurang mendapatkan dukungan dari ibu.

Hasil penelitian menunjukkan bahwa ada dukungan ibu terhadap remaja putri dalam menghadapi menarche di SD Negeri Lomanis 01 Kecamatan Cilacap Tengah Kabupaten Cilacap tahun 2013 $62,2 \%$ ibu mendukung anaknya menghadapi menarche dan 37,8\% ibu kurang mendukung. Banyaknya ibu yang dikategorikan mendukung dikarenakan sebagian besar sudah mengetahui menstruasi dengan baik dan memiliki pengalaman yang tidak mudah dilupakan ketika menstruasi pertama. Berdasarkan pengetahuan dan pengalamannya tersebut ibu banyak memberikan masukan dan informasi tentang menarche kepada putrinya agar tidak cemas dan takut dalam menghadapinya (Nilawati, 2013).

Orang tua adalah pendidik pertama bagi anak-anaknya. Fungsi sosialisasi dan pendidikan yaitu menyadari, merencanakan dan menciptakan lingkungan keluarga sebagai wahana pendidikan dan sosialisasi anak yang pertama dan utama. Menyadari, merencanakan, dan menciptakan kehidupan keluarga sebagai pusat tempat anak anak dapat mencari dari pemecahan dari berbagai konflik dan permasalahan yang dijumpainya baik di lingkungan masyarakat maupun sekolahnya (Ali, 2010).

Sejalan dengan hasil penelitian di Deli Serdang yang menyatakan berdasarkan hasil uji statistik chi-square dengan tingkat kemaknaan $\alpha=0,05$ diperoleh nilai $p=0,006$ yang berarti bahwa ada hubungan sumber informasi dengan kecemasan saat mengalami menarche. ${ }^{(13)}$ Hal ini juga sejalan dengan penelitian di Klaten diperoleh $\mathrm{p}$ value $<0,05$ yaitu $\mathrm{p}<0,001$ yang menunjukkan ada hubungan fungsi keluarga dengan kejadian sindrom pramenstrual pada remaja putri, yang berupa disfungsi fisik, perilaku, dan sosial yang dapat mengganggu kehidupan (Janitra, 2015).

Menstruasi adalah salah satu periode penting dari seorang wanita. Pengetahuan remaja tentang menarche, sumber pengetahuan, problem yang ditemukan, respon terhadap masalah dan cara yang digunakan untuk mengatasi masalah menstruasi akan berakibat pada seluruh kehidupan wanita. Apabila wanita tersebut sehat, maka akan diperoleh generasi sehat pada masa yang akan datang (Karakoc et all, 2013)

Sama halnya dengan hasil penelitian di Nepal tentang komunikasi ibu dan anak dengan kesiapan remaja dalam menghadapi menstruasi pertama (menarche) pada siswi di Shree Himali. Pada penelitian ini, ditemukan bahwa sumber informasi pertama paling banyak didapatkan remaja putri dari ibu sebanyak 39,3\% dan kakak sebanyak 18,3 \% dalam menghadapi menstruasi pertamanya (menarche) yang membuat remaja putri lebih siap untuk menghadapi menarche. Sedangkan data tambahan lainnya remaja mendapatkan informasi dari hasil wawancara menunjukkan bahwa media informasi seperti, buku, majalah, guru, teman sebaya, dan tenaga kesehatan juga memberikan peran pada kesiapan siswi di Nepal dalam menghadapi menarche (Sapkota et all, 2013).

Pendidikan tentang kesehatan reproduksi merupakan masalah penting yang perlu mendapatkan perhatian dari semua pihak. Mengingat banyaknya efek yang terjadi baik fisiologis atau psikologis pada saat mengalami menarche yang dapat menimbulkan kecemasan, remaja putri perlu mendapatkan dukungan dari keluarga salah satunya adalah dukungan informasional yang dapat diperoleh dari orangtua. Keluarga mempunyai pengaruh yang cukup besar bagi 
perkembangan remaja karena keluarga merupakan lingkungan sosial pertama, yang meletakkan dasar-dasar kepribadian remaja.

Fungsi keluarga dalam memberi informasi terutama ibu mengenai menstruasi pertama (menarche), memberitahukan kalau menstruasi adalah hal normal pada wanita, dan tidak perlu merasa maludapat mencegah timbulnya kecemasan. Peran fungsi keluarga memberikan informasi kepada remaja putri untuk menjaga kesehatan reproduksi akan menunjukkan kasih sayang, memberikan rasa aman, bertanggung jawab, dan mampu dalam menjaga sistem reproduksinya sehingga remaja putri usia sekolah dasar lebih siap menghadapi menarche. Fungsi keluarga sangat dibutuhkan agar anak merasa diperhatikan sehingga dapat mengurangi kecemasan menghadapi menarche.

Lebih separuh responden yang fungsi keluarga kurang mengalami kecemas menghadapi menarche pada remaja putri usia sekolah dasar di SD Negeri 064988 Medan. Peneliti menyarankan kepada pihak sekolah diharapkan dapat memberikan tambahan pengetahuan dan informasi kesehatan reproduksi khususnya tentang menarche untuk siswi agar dapat mengurangi kecemasan menghadapi menarche. Kemudian kepada orangtua diharapkan dapat memberikan informasi kesehatan reproduksi terutama mengenai menstruasi pertama (menarche).

\section{KESIMPULAN DAN SARAN}

Lebih separuh responden yang fungsi keluarga kurang mengalami kecemas menghadapi menarche pada remaja putri usia sekolah dasar di SD Negeri 064988 Medan. Peneliti menyarankan kepada pihak sekolah diharapkan dapat memberikan tambahan pengetahuan dan informasi kesehatan reproduksi khususnya tentang menarche untuk siswi agar dapat mengurangi kecemasan menghadapi menarche. Kemudian kepada orangtua diharapkan dapat memberikan informasi kesehatan reproduksi terutama mengenai menstruasi pertama (menarche).

\section{Ucapan Terima Kasih}

Terimakasih kepada Prof. Dr. Dra. Ida Yustina, M.Si selaku Dekan Fakultas Kesehatan Masyarakat Universitas Sumatera Utara, Ir Etti Sudaryati, M.K.M, Ph.D selaku Ketua Program S2 Fakultas Kesehatan Masyarakat Universitas Sumatera Utara, Sri Rahayu Sanusi, S.K.M, M.Kes, Ph.D dan Prof. Dr. Ir. Evawany Y Aritonang, M.Si selaku dosen pembimbing yang telah membimbing dan mengarahkan penulis hingga penelitian ini selesai.

\section{REFERENSI}

Sukarni, I., ZH, M. 2013. Kehamilan, Persalinan, dan Nifas. Cetakan I. Yogyakarta: Nuha Medika.

Afrinis, N. 2014. Hubungan Status Gizi dengan Menarche pada Siswi Kelas IX SMPN 1 Kampar Kecamatan Kampar Tahun 2014, Jurnal Kebidanan, STIKes Tuanku Tambusai. Riau.

Putri, G. 2015. Hubungan Usia Saat Menarche dengan Pola Siklus Menstruasi dan Dismenorea Remaja Putri di SMP Shafiyyatul Amaliyyah Medan. Skripsi. Universitas Sumatera Utara. Medan.

Estri, B., A. 2012. Hubungan Peran Orang Tua dalam Pendidikan Menstruasi dengan Perilaku Saat Menstruasi pada Remaja Putri Kelas VIII di SMP N I Banguntapan Bantul. Naskah Publikasi. Sekolah Tinggi Ilmu Kesehatan Yogyakarta.

Pulungan, F. 2012. Pengaruh Fungsi Keluarga Terhadap Pemahaman Remaja Putri Usia Sekolah Dasar tentang Menarche (Studi Kasus di SD Negeri 066667 dan SD Negeri 066433) Medan. Tesis. Universitas Sumatera Utara. Medan. 
Prasetyo, M.,G. 2016. Hubungan Dukungan Orang Tua dengan Kesiapan Anak Remaja Putri Menghadapi Menarche di SD Negeri Dukuh 01 Mojolaban Sukoharjo. Naskah Publikasi. Fakultas Ilmu Kesehatan Universitas Muhammadiyah Surakarta. Surakarta.

Hawari, D. 2013. Stres, Cemas, dan Depresi. Cetakan VII. Jakarta: Balai Penerbit Fakultas Kedokteran Universitas Indonesia.

Karakoc, A., Bingol, F., Ocakci, A., F. 2014. Menarche and First Emotional Reaction of Turkish Adolescent. Marmara University Faculty of Health Science, Istambul. Turkey.

Ali, Z. 2010. Pengantar Keperawatan Keluarga. Jakarta: Penerbit Buku Kedokteran EGC.

Ulfa, E. Mardiyanto, R. A., Rusmariana, A., Ratnawati. 2012. Hubungan Dukungan Keluarga dengan Tingkat Kecemasan pada Remaja Putri dalam Menghadapi Menarche di MI Salafiyah Simbang Kulon 02 Kabupaten Pekalongan. Skripsi. STIKES Muhammadiyah Pekajangan Pekalongan. Pekalongan.

Undang-Undang Nomor 52 tahun 2009. Tentang Perkembangan Kependudukan dan Pembangunan Keluarga.

Nilawati, I. 2013. Hubungan Dukungan Ibu dengan Kecemasan Remaja dalam Menghadapi Menarche di SD Negeri Lomanis 01 Kecamatan Cilacap Tengah Kabupaten Cilacap Tahun 2013. Jurnal Ilmiah Kebidanan. Purwokerto.

Desi, F. 2016. Faktor-faktor yang Berhubungan dengan Tingkat Kecemasan Remaja Putri saat Mengalami Menarche di SMP Jaya Krama Kecamatan beringin Kabupaten Deli Serdang Tahun 2016. Tesis. Universitas Sumatera Utara. Medan.

Janitra, R., A. 2015. Hubungan Antara Fungsi Keluarga dengan Kejadian Sindrom Pramenstrual pada Siswi SMAN 2 Klaten. Naskah Publikasi. Fakultas Kedokteran Universitas Muhammadiyah Surakarta. Surakarta.

Sapkota, D., Sharma, D., Budhathoki S., S., Khanal, V., K., Pokharel, H., P. 2013. Knowledge and Practises Regarding Menstruation among School Going Adolescent in Nepal. Journal of Kathmandu Medical College, Vol. 2, No. 3, Issue 5, Jul-Sep. Nepal. 